\title{
The problem of racism in Kathryn Stockett's novel The Help
}

\begin{abstract}
This article analyzes Kathryn Stockett's The Help (2009) with the main focus on the presentation of the ubiquitous problem of racism experienced by African Americans in the United States. Specifically, it demonstrates shameful, humiliating and unbearable living conditions of black maids in the 1960s in Jackson, Mississippi. It discusses different types of racism, such as overt, institutional, and structural, which occur in this community. Additionally, this paper provides an overview of the history of racism in the USA. The purpose of this article is to examine the history of interracial relationships in the USA, which sheds light on the problem of white supremacy, as well as demonstrates the damaging consequences of racial prejudice. However, the main objective of the paper is to analyse the relationships between white and black characters inhabiting Jackson, Mississippi as depicted in Kathryn Stockett's The Help.
\end{abstract}

Keywords: Kathryn Stockett, racism, the USA, Mississippi, black maids, discrimination, Jim Crow laws.

\section{Introduction}

The plight of African Americans in the United States is the phenomenon which has been widely studied by scholars and academics from different disciplines. Racism has been experienced by the Blacks since slavery was introduced in the USA as a system after 1619 landing of the first group of 20 Africans in Jamestown. This fact makes us realise that the USA has a long history of gradually changing relationships between black and white Americans. This article, therefore, aims at presenting many considerable changes in problematic interracial relationships as well as accentuating huge differences in standards of living experienced by the Whites and the Blacks. It is worth noting that African Americans bore the brunt of the changes.

The paper puts the main emphasis on describing the everyday struggles of African Americans trying to live with dignity and respect as portrayed in Kathryn Stocketts' novel The Help. Set in the segregated South, the book contains detailed depictions of events which took place from the late summer of 1962 through 1964 in Jackson, Mississippi. Specifically, the article highlights unbearable living conditions of African American maids employed by white Americans with a strong racial prejudice towards the Blacks. Moreover, not only does The Help demonstrate fictional events 
taking place in the blindly racist community of Jackson, but it also depicts events which actually took place. This adds authenticity to the work.

\section{The situation of African Americans in the USA}

Since the introduction of slavery as a system in 1661 in Virginia, American history of a racism has been fraught with series of ups and downs in relationship between white Americans and African Americans. This was a point of history when the conflict between them began. African Americans were treated as if they were inferior. They worked for a long time, sometimes from sunset to sunup. The system of oppression lasted until it was abolished before the end of the American Civil War in 1865. The introduction of the Thirteen Amendment to the United States Constitution changed the lives of African Americans completely. From this moment on African Americans, former slaves, were considered human beings and they also were given the right to vote. They started to educate themselves and, what was more important for them, were allowed to possess their own land. Furthermore, a year later, in 1866 the first Civil Rights Act was enacted. It strengthened the position of African Americans by giving them American citizenship and therefore equal treatment before the law. Nonetheless, racial discrimination did not disappear as African Americans still were considered inferior and subservient. In some states, especially in the South, white Americans strived to prevent them from exercising the right to vote by means of literacy tests and high poll taxes. Moreover, the Blacks were paid less than white Americans for the same work. The next example of the Whites resentment toward the Blacks was forming secret organizations like the Ku Klux Klan which promoted white supremacy. Members of this organization terrorized their black neighbours at night wearing masks and costumes to terrify the Blacks. During the Reconstruction era, in 1877 there were also strict Jim Crow laws legislated. This humiliating set of rules and regulations officially segregated the Blacks and the Whites throughout the Southern States of America affecting almost every sphere of their life (Fisher 2006: 48-49).

At the beginning of the twentieth century the situation concerning race relations did not improve. In the USA there was a rise of racist behaviour and shocking increase in the racist attacks. During World War I, African Americans started to migrate in large numbers to western and northern America. They hoped that this would give them a better chance of gaining knowledge and a rewarding, well-paid job. However, many black people became unemployed as they were not educated or skilled enough to take up a job. As a result, it was difficult for them to make their ends meet. Many of them lived in abject poverty inhabiting slums (Greenberg 2009: 15-17).

The next period of great changes in race relationships between the Whites and the Blacks in the USA was World War II. Some of the black Americans started to achieve success in a large number of fields. For instance, Gwendolyn Brooks won a Pulitzer Prize for poetry, Sidney Poitier won an Academy Award for Best Actor, and Hulan Jack became the first black Manhattan borough president. Nevertheless, even if the lives of some African Americans improved considerably, most of them still suffered from acute poverty or unemployment (Greenberg 2009: 29-31). Then, the period of 1960s began with the so-called 'sit-in protests' during which African Americans oc- 
cupied a particular place preserved for white people. By means of such protests they showed that they were no longer going to acquiesce to unequal treatment. Nevertheless, apart from taking part in nonviolent protests, some of African Americans were so tired of being mistreated that they did not see other alternatives but to fight for their rights by taking part in riots. Moreover, in order to maintain struggle for justice, peace, and equal treatment for African Americans, during the 1960s the Blacks were represented by a generation of courageous black leaders, such as Martin Luther King Jr. who paid for the defence of the Blacks' dignity with his life (Fisher 2006: 106-109).

\section{The lives of African Americans in The Help}

Kathryn Stockett's The Help, published in 2009, brings up the issue of racism in the Southern United States by portraying relationships between white and black Americans from late summer of 1962 through 1964 in Jackson, Mississippi. The book is written from the perspective of three different women: Eugenia Phelan (best known for her nickname Skeeter) - a white young college graduate who wants to be a journalist and undertakes a monumental task of writing a book about black maids' struggles from their point of view, Aibileen Clark - a wise black maid who raised seventeen white children, and Minny Jackson - an outspoken black maid who persuades other black maids to help Skeeter to write the book. Each narrator presents her own background, thoughts, and the desire for change. However, not only does the novel depict the white employers' discrimination against black maids, but also it focuses on prejudiced treatment of the Blacks by white Americans of all ages and from all walks of life.

Set in the segregated South of the 1960s, The Help provides a detailed description of the events connected with daily lives of Mississippians. Kathryn Stockett demonstrates how strong is the bias of the Whites toward black residents of Jackson by means of numerous examples of racist behaviour. Apart from fictional events, the novel also demonstrates events which actually took place, thus adding authenticity to the work. For instance, the book clearly depicts the fear of death and brutality that African Americans experienced after Medgar Evers' assassination. When the black inhabitants of Mississippi find out that he was killed by members of the Ku Klux Klan they are scared to death and avoid leaving their homes for fear of being shot. The situation is even more dramatic because of the fact that Evers, the black field secretary for NAACP (the National Association for the Advancement of Colored People) who fought against the Blacks' exploitation, was shot in front of his house right before his children's eyes. Therefore, the Blacks realise that their lives are always under threat just because of their skin colour. As one of the main protagonists of The Help, the black maid Aibileen, states:

for days and days, Jackson, Mississippi's like a pot of boiling water. On Miss Leefolt's tee-vee, flocks a colored people march up High Street the day after Mister Evers' funeral. Three hundred arrested. Colored people say thousands a people came to the service, but you could count the whites on one hand. The police know who did it, but they ain't telling nobody his name (Stockett 2009:196). 
This entire event demonstrates that white Mississippians have no compunctions about taking African Americans into custody even if they do not commit any crime. Moreover, white perpetrators always remain unknown to the general public while the Blacks are severely punished for even slight conflicts with the Whites.

The next historical event which the author includes as a plot point in The Help is the long struggle of African Americans against Jim Crow laws. For instance, Stockett incorporates into her narration a description of the sit-in protest at Brown's Drug Store. Minny Jackson, the black maid, states that "a bunch of white teenagers stand behind the five protesters on their stools, jeering and jabbing, pouring ketchup and mustard and salt all over their heads" (Stockett 2009: 219). The event clearly displays the white teenagers' strong prejudicial attitudes, as well as racial hatred and aggression toward the Blacks. Thus, Stockett suggests that white children are taught by their parents and teachers from a very young age to hate the Blacks as the white adults want to prevent from their integration (Sturkey, Hale 2015: 12). Then it is difficult or even impossible for the white teenagers to get rid of racial stereotypes and behaviour.

Another important aspect of Jim Crow laws demonstrated in the novel is the huge division between white Americans and African Americans concerning facilities used by them. The humiliating set of rules and regulations stated that the black inhabitants of Jackson are not allowed to use shops, restaurants, and libraries reserved for the Whites only. The black maids in The Help, e.g. Aibileen and Minny, sometimes have to buy something in the shops for the Whites for the white families they work for. However, they can enter the shop provided that they wear white uniforms. What is important to notice is the fact that the schools, libraries, and shops attended by the Blacks are completely different from the ones attended by the Whites. In the Stockett's novel this is illustrated in a description of the shop for the Blacks called Piggly Wiggly "with the potatoes having inch-long eyes and the milk almost sour" (Stockett 2009: 42). In addition, it is essential to mention that when the Blacks refuse to adhere to Jim Crow laws they are severely punished. For instance, Skeeter says that when there was a sit-in protest at the white library a few years ago, "the police department simply stepped back and turned the German shepherds loose" (Stockett 2009: 154). Stockett also stresses the fact that black inhabitants of Jackson can hardly make ends meet due to racial discrimination in terms of employment. They are given only menial jobs such as maids, charwomen, and fast-food workers which are, of course, low-paid. In addition, their white employers perpetuate racial stereotypes about the Blacks' aggression, laziness, irresponsibility, and lack of intelligence. Thus, the black residents of Jackson often live in abject poverty inhabiting the poorest part of the city, which is clearly exemplified by means of a description of Hotstack, Constantine's (Skeeter's former maid) neighbourhood. When Skeeter recollects one day of walking along the neighbourhood with Constantine she remembers "the colored five-and-dime store, then a grocer with hens laying in back, and all along the way, dozens of shacky-looking roadside houses with tin roofs and slanting porches" (Stockett 2009: 61). Living in such poor conditions causes the black characters of The Help want to change their lives fraught with pain, hunger, and suffering. As a result, it leads to taking part in violent demonstrations, like the one in the library described by Skee- 
ter. Therefore, Stockett, by combining the actual historical events with the fictional ones, offers a true representation of the interracial relationship between inhabitants of Mississippi which at that time was regarded as one of the most racially oppressive states in the USA (Watson 2010: 10).

\section{Different types of racism in The Help}

Stockett's The Help offers a multitude of examples of racial discrimination against black inhabitants of Jackson, Mississippi. Almost every white character demonstrated in the novel shows hatred toward the Blacks and treats them with scorn and contempt as if they were second-class citizens without full rights and benefits. Therefore the author of the novel clearly reveals that deeply-rooted racism permeates every aspect of the segregated society of Jackson.

\section{Overt racism}

The characters of The Help have to deal with different forms of racism on a daily basis. However, most often they are victims of overt racism, which manifests itself in hatred and contempt towards other people due to their belonging to a different race. It is characterised by assumptions of racial superiority made by the white people who consider themselves to be better in terms of intelligence or personality traits. This form of racism is easily observable as overt racism action "takes place only if a harm is inflicted or a benefit withheld either because of the perpetrator's racial bias against the victim or because of that perpetrator's obliging the race prejudice of others" (Ezorsky 1991: 9). This type of racism is omnipresent in the prejudiced community of Jackson, which is clearly pointed out by Hilly Holbrook's negative behaviour toward her black maid Minny Jackson and the black maid, Aibileen Clark, who works for her friend Elizabeth Leefolt. According to Garcia, Hilly is "the self- serving power broker in this female world of white social elites" (Garcia, Young, and Pimentel 2014: 54). Holbrook is the president of the Jackson Junior League which aims at helping PSCAs (The Poor Starving Children of Africa). During one of the meetings, when a member of the league asks her if it would not be better for them to send money to the poor rather than canned food whose transport is very costly, she says that they "cannot give these tribal people money" (Stockett 2009: 175). She also adds that the Blacks "are likely to go to the local voodoo tent and get a satanic tattoo with [their] money" (Stockett 2009: 175). The entire event displays Hilly's patronising attitude toward the Blacks and lack of respect for them. What is more, when Holbrook meets her friends at Elizabeth's house for a weekly bridge game, she says that African Americans disseminate different kinds of diseases and that she wants to maintain separation of black maids from white families by means of separate bathrooms for the maids. She tries to pass a bill which would require all Mississippians to build outdoor bathrooms for their black maids which she calls "a disease-preventive measure" (Stockett 2009: 8). As a result, after a few days Aibileen has to use a separate bathroom outside the Leefolt's house. Moreover, "Hilly raises her voice about three octaves higher when she talks to colored people" (Stockett 2009: 157). Her manner of speaking demonstrates that she treats African Americans as if they were inferior and not as intelligent as the Whites. What is more, when Hilly finds out that Aibileen helped Skeeter to write a book about 
the black maids in Jackson employed by white Americans (including Hilly and Elizabeth), Hilly makes Elizabeth dismiss Aibileen accusing the black maid in a completely unjustified way of stealing her three pieces of cutlery. As Mills states in her book, "it is no wonder that Aibileen declares to aggressively racist Miss Hilly [...] 'You a godless woman', for only a woman without knowledge of God and His mercy could be so unrelentingly racist” (Mills 2016: XI).

The matter of overt racism is also highlighted by a racist attitude of Elizabeth Leefolt who blindly follows Hilly Holbrook. When her little daughter, Mae Mobley, uses Aibileen's bathroom, Elizabeth tells her that Aibileen is dirty and diseased. Therefore, Leefolt enforces prevailing racist behaviours and attitudes. This situation reveals that due to adults' prejudice toward the Blacks, racism is handed down over the ages from generation to generation.

The reader of the novel is presented with overt racism also through the mentioning of several incidents. For instance, the author of The Help describes Robert's case. The grandson of the black maid Louvenia Brown is beaten with a tire iron by the Whites after using the unmarked bathroom reserved for white Americans at Pinchman Lawn and Garden. As a result of the beating, he becomes blind. Stockett also mentions the Whites burnt the house of Aibileen's cousin, Shinelle, in Cauter Country because of her participation in elections. The next example of overt racism can be seen when white Americans cut off the tongue of Aibileen's husband's cousin as she talked with somebody from Washington about the Ku Klux Klan.

\section{Institutional racism}

Stockett also presents many situations demonstrating institutional racism. According to Shirley Jean Better, this kind of racism often goes undetected and "moves surreptitiously throughout [...] social institutions, hardly making a ripple unless you are the recipient of its harsh treatment" (Better 2002: 48). Institutional racism expresses itself in unfair treatment of people who do not belong to the white race in institutions such as schools, media systems, and the government. The mistreatment is observable when some people in control of institutional power use it to devoid people belonging to different race of equal opportunities. The book clearly reveals the situations by means of racist treatment of black maids who work for white American families. As pointed out by Garcia, "beyond the overt racial and class divisions present in America today, the assumption that black (and brown) women are innate caretakers has a much longer history than the current domestic employment practices" (Garcia, Young, and Pimentel 2014: 58). Therefore, due to negative stereotypes perpetuated by white Americans, African Americans in The Help are given only menial jobs like maids, refuse collectors, and plantation workers.

What is important to note is the fact that the white people in control of institutional power often mistreat their employees, which is shown by the example of relations between Elizabeth Leefolt and Aibileen Clark, the black maid who works for her. The detailed descriptions of Elizabeth's behaviour clearly reveal that her black maid is discriminated against in her workplace. The best example of racial oppression is building by the Leefolts a separate bathroom in the garage for 
Aibileen. What is more, during her working time Aibileen is often offended by Elizabeth's friend, Hilly Holbrook, who says that African Americans should be separated from white Americans as she believes they disseminate different kinds of diseases. It is essential to mention that Aibileen "work[s] for Miss Leefolt eight to four, six days a week except Saturdays" (Stockett 2009: 16). She gets "forty-three dollars [every] Friday, which come[s] to \$172 a month" (Stockett 2009: 16) and she is afraid to even ask Leefolt for minimum wage even if she hardly makes ends meet. She is dismissed "when the babies get too old and stop being color-blind" (Stockett 2009: 128). The author of The Help mentions that Aibileen raised seventeen children, which means that she had to change her job many times. Furthermore, according to Mills,

anything that happen[s] during the course of any day a black woman work[s] in a white home [is] almost invariably her fault. [...] If a white child fell, it [is] because the black woman [is] not attentive enough. If the biscuits [are] burned or the chicken slightly undercooked, then, in the absence of slavery-sanctioned corporeal punishment, docked wages—or firing—would be the result (Mills 2016: XII).

The next example portraying institutional racism is the way in which the Whites treat Aibileen's son, Treelore, who dies two years before the novel opens (when he was 24). One rainy night when he works at the Scanlon-Taylor mill "lugging two-by-fours to the truck, splinters slicing all the way through the glove" (Stockett 2009: 2) he slips off the loading dock and falls down the drive. The person who operates a tractor-trailer does not notice Treelore and crushes his lungs. Then "his broken body [is] thrown on the back of a pickup by the white foreman" (Stockett 2009: 153). By the time Aibileen finds out about the accident Treelore is dead. As the maid states, Treelore was "too small for that kind of work, too skinny, but he needed a job" (Stockett 2009: 2). Treelore's case shows that white employers do not consider their black employees' safety as an important issue. African Americans are given the most physically demanding jobs which often are also the most dangerous. This situation clearly indicates that Treelore, like other young black men, had no other possibility to earn money for his family but to take up a low-paid, menial job.

\section{Structural racism}

In The Help there are also examples of structural racism, which manifests itself in unequal distribution of goods and resources for achieving aims due to different colour of skin, as discrimination against black Americans is deeply-rooted in white inhabitants of Jackson who aim at concealing racism rather than eradicating it (Garcia, Young, and Pimentel 2014: 23). The work of Sam Porter reveals that "individuals will enjoy more or less powerful enabling positions in a society which displays structural racism, depending on how they are categorised in racist terms" (Porter 1993: 597). This unequal distribution existed a long time ago and now people are put within some kind of groups whose members are given more or less powerful positions than others. For instance, the Whites in The Help show their supremacy over the Blacks when they do not allow them to expand 
into white neighbourhoods. According to Aibileen, "Jackson's just one white neighbourhood after the next and more springing up down the road. But the colored part a town, we one big anthill, surrounded by state land that ain't for sale. As our numbers get bigger, we can't spread out. Our part a town just gets thicker" (Stockett 2009: 12). This passage reveals that African Americans are treated unfairly by the US government whose members strive to avoid integration of white and black Americans. Even if they live in the same town, according to Skeeter, "the colored part of town seems so far away when, evidently, it's only a few miles from the white part of town." (Stockett 2009: 143).

Structural racism in The Help is also pointed out by deeply-rooted beliefs held by white inhabitants of Jackson that the Blacks are thieves and liars. The novel clearly portrays the negative attitude of the Whites towards African Americans when Minny, the black maid who works for the Holbrooks, is unjustifiably accused by Hilly of stealing her silver. The false accusation ruins Minny's reputation and creates an enormous problem for her to find a job as the white residents of Jackson consider the Whites to be honest and trustworthy while maintaining that the Blacks do not deserve to be trusted. The white Mississippians completely believe in the rightness of Hilly's accusation. They do not even assume that it is a part of her plan to get revenge on Minny for using the Holbrooks' toilet during a brutal storm.

Stockett also illustrates structural racism by the fact that the Blacks have to obey rigid Jim Crow laws which maintain the racial hierarchy stressing white supremacy and control over African Americans. The humiliating set of rules prevents them from living decent lives as the Blacks are deprived of even basic facilities. For example, black inhabitants of Jackson cannot use shops, restaurants, swimming pools, and libraries reserved for whites only. It is worth mentioning that when African Americans refuse to obey these rules, the groups such as the Ku Klux Klan fight against them. Its members often terrorise the Blacks, burn their houses, beat them, and shoot to death for not obeying Jim Crow laws.

Moreover, what is important to mention is that some people of power in the community of Jackson like Hilly Holbrook, the leader of the Junior League, is expected to be devoid of racial discrimination. Holbrook, who is responsible for the organization supporting the Blacks in Africa, should set a good example for Mississippians. Nevertheless, Hilly's behaviour reveals her strong bias toward African Americans. She is a hypocrite who "send[s] money to colored people overseas, but not across town" (Stockett 2009: 280). Although she helps The Poor Starving Children of Africa, she simultaneously strives to maintain racial segregation in her town, which can be definitely regarded as the example of structural racism.

\section{Prejudice and injustice experienced by the black maids}

Stocket's novel demonstrates racial discrimination which affects all black characters who live in the deeply prejudiced society of Mississippi during the Jim Crow era. She presents unbearable living conditions experienced by the black inhabitants of Jackson, cruel treatment of the Blacks who 
take part in protests fighting for equal rights, and humiliating black workers by white Americans. However, the author of The Help puts the main emphasis on portraying the suffering of black maids who work for white families looking after their children, cooking and serving food, and cleaning their houses. The Stockett's novel deals with the problem of maid's abuse as she demonstrates in her book numerous examples of prejudiced behaviour towards the black maids. As Yanick St. Jean states in his book, "for an African American it takes great strength and courage to 'do tough' in the face of discrimination and misrepresentations, misconceptions, and distortions of black women at the hands of white Americans" (Yanick 1998: IX).

It is worth mentioning that African American women in The Help are treated much more harshly than black men as they are burdened by the stigma of race as well as the stigma of sex. Not only are they mistreated by white Mississippians but also by their husbands and fathers. For instance, Minny Jackson, the black maid working for the Holbrooks, had really difficult childhood due to her "no-good drunk daddy" (Stockett 2009: 38) because of whom she was about to drop out of school in order to support her family. After school she spent much of her time performing household chores such as cooking and cleaning. The situation experienced by the Jacksons clearly reveals that only women were responsible for earning their livelihood while man did nothing but drowned his sorrows in alcohol. What is more, when Minny starts her own family she is constantly beaten by her husband Leroy who often also shouts at her. At the end of the novel Leroy even tries to kill Minny as he finds out that he lost his job because of his wife. He does not hit Minny only when she is pregnant, which is why Minny gets pregnant all the time and they have five children. Minny is continually worried about "[her] husband Leroy coming home drunk [very frequently]. [Leroy] knows that's the one thing [she] can't stand after nursing [her] drunk daddy for ten years, [Minny] and [her] Mama working [...] to death so he had a full bottle" (Stockett 2009: 51) but he does nothing to change his damaging behaviour. In addition, when Minny talks with Aibileen, her best friend, she says that "plenty of black men leave their families behind like trash in a dump, but it's just not something the colored woman do. [They've] got the kids to think about" (Stockett 2009: 310-311).

The next woman who suffers owing to being a woman and her skin colour is Aibileen - the black maid who works for the Leefolts. As a young teenager she had to drop out of school to support her family by working as a maid. She was, therefore, deprived of a normal, happy childhood. Then, when her son Treelore was born, her dark-skinned husband Clyde left her to raise the child alone. Thus, Stockett depicts black males in her book in a negative light, making black maids victims of their husbands' and fathers' brutal and inhumane behaviour.

The black maids portrayed in The Help are often mistreated by their fathers and husbands. However, the author of the novel focuses mostly on demonstrating dehumanizing and humiliating working conditions experienced by them. Stockett makes reader realise that in the small community of Jackson, where racism permeates all aspects of life, "no concept of equality [can] govern $\mathrm{maid} / \mathrm{mistress}$ interactions in the homes of whites just as no concept of equality govern[s] the society in which these women [are] employed" (Mills 2016: XII). 
As an example of dealing with humiliation Stockett describes Aibileen Clark raising her eighteenth white child, Mae Mobley, the daughter of the Leefolts. The maid faces racial discrimination and prejudice on a daily basis. Even though she does her best taking care of Elizabeth Leefolt's child, cooking, and cleaning, she is not appreciated by her employer. Conversely, Aibileen is frequently reprimanded by her, for example, when she talks with Elizabeth's friend Skeeter during her working hours. Such a situation shows that she is treated like Leefolt's property. In addition, Aibileen is used to be given worn-out clothes by her white employers. The black maid, who lives in abject poverty, has no choice but to wear clothes which earlier belonged to her white employers as she does not possess enough money to buy new ones. Furthermore, the Leefolts build a separate toilet for her as Elizabeth is persuaded by her friend Hilly that it is the only way to prevent their family from being infected with dangerous diseases which, she states, are disseminated by the Blacks. This is probably the most embarrassing situation that has ever happened to Aibileen. What is important to mention is the fact that Aibileen, who is treated like a second-class human being, never complains of being tired and discriminated. Moreover, Aibileen never talks back to Leefolt as well as to her racially prejudiced friend Hilly who often offends African Americans by creating and perpetuating racial stereotypes showing the Blacks as unintelligent, dirty, and lazy. Nevertheless, Aibileen perseveres in overcoming all the obstacles of her life without feeling sorry for herself.

The next example of prejudiced treatment of black maids is demonstrated by the case of Constantine, who was employed by the Phelans. Skeeter, the Phelans' daughter, "praises Constantine as a nurturer who would bring her home to the black segregated side of town simply due to the love that she had for the white child in her care" (Garcia, Young, and Pimentel 2014: 68). Nevertheless, after working for Phelan family for twenty-nine years Constantine was dismissed by Charlotte Phelan, Skeeter's mother, due to Constantine's illegitimate daughter's rude behaviour. What was even more cruel, Charlotte told Lulabelle that "[her] mama hadn't been sick a day in her life. She [had given Lulabelle] up because [she was] too high yellow" (Stockett 2009: 364). However, what is essential to note is the fact that Constantine gave her daughter for adoption as "being [African American] with white skin [...] in Mississippi it's like you don't belong to nobody" (Stockett 2009: 358). When Constantine was noticed with her white daughter "[w]hite folks would stop her, ask her all suspicious what she doing toting round a white child. [...] Even colored folks... they treat[ed] her differently, distrustful, like she [had] done something wrong." (Stockett 2009: 358). By means of Constantine's case Stockett stresses the fact that "[b]lack women are expected to love their white families unconditionally" (Garcia, Young, and Pimentel 2014: 68) and devote considerable efforts to performing household chores as effectively as possible while white Americans do not pay attention to their emotions, mistreating and humiliating them all the time.

The black maids in The Help, therefore, are treated unequally by their white employers even though they are indispensable for their families. For instance, African American maids' salaries do not correspond to the great effort put into their jobs. Minny, after working as a maid for five years, is paid one dollar per hour, which makes her "feeling kind of ashamed" (Stockett 2009: 37) as she is paid below the legal minimum wage. Similarly, Aibileen is paid by the Leefolts 172 dol- 
lars a month, working from eight to four o'clock, as a result of which she barely makes ends meet. Stockett demonstrates in her book that because of such appallingly low salaries the black maids and their families live in a deep poverty. For instance, when Minny was fourteen, "[b]irthdays were the only day of the year [she] was allowed to eat as much as [she] wanted" (Stockett 2009: 38). Thus, as a result of poor living conditions together with unfair treatment by the white community the Blacks tend to have a lower self-esteem than the Whites. This phenomenon is illustrated in Aibileen's case when she sits in her kitchen after supper and observes a big cockroach. She compares this insect to herself noticing that it is blacker than she is. Furthermore, Aibileen feels her inferiority to white Americans not only due to her colour of skin, but also because of her ancestry. When she is asked by Skeeter, who writes a book about the plight of black female domestic workers in the USA, whether she always thought she would be a maid, Aibileen replies in an affirmative manner. The black maid tells her that she knew that she was going to work as a maid as her mother was a maid and her grandmother had been a house slave. Aibileen does not even consider looking for another job as she finds it impossible for her to get a job which would provide her with sufficient income, a sense of accomplishment, and overall satisfaction.

The Help is also fraught with references to racist incidents suffered by black maids which are mentioned in the conversations of the main characters of the novel. For instance, when Aibileen talks with her black colleague Ernestine, who works for the Holbrooks, she finds out that Flora Lou, a black maid employed by Miss Hester "who everybody think is real sweet" (Stockett 2009: 433), was given "a special 'hand wash' to use ever morning” (Stockett 2009: 433). As Ernestine says, it turned out to be "straight bleach" (Stockett 2009: 433). As a result, Flora Lou had a burn scar which she showed Ernestine. In addition, during Minny's conversation with Aibileen they recall unpleasant incidents connected with Minny's former racist white employers. As an example, Aibileen brings up the memory of Mister Charlie who thought it had been funny to humiliate Minny by name-calling and insults and his wife "who [made her] eat lunch outside, even in the middle a January, [...] even when it snowed that time" (Stockett 2009: 227). Then, when Aibileen starts to talk about the incident connected with Miss Roberta she cannot stop laughing as the white employer made Minny "sit at the kitchen table while she [was trying out] her new dye solution on [Minny]" (Stockett 2009: 227). This caused Minny's hair became blue and, according to her husband Leroy, she "look[ed] like a craker from outer space" (Stockett 2009: 227). The situation was certainly not so funny for Minny as it "took three weeks and twenty-five dollars to get [her] hair black again" (Stockett 2009: 227). Therefore, all the events illustrate that black female domestic workers were frequently abused in numerous ways. They were accustomed to being treated like sub-humans and facing hardships on a daily basis.

\section{Conclusions}

Stockett's novel "make[s] clear that problematic interactions across racial lines remain an ongoing dynamic that informs and shapes what happens to black women when they go to work as maids and caregivers in white women's houses" (Mills 2016: XIII). The book clearly demonstrates that 
white employers look down on black maids. The maids are offered harsh and humiliating treatment which makes them feel inferior to white Americans. Nevertheless, at the same time this treatment causes their desire to change their poor existence which is the reason for their willingness to share their unpleasant experience with white and black Americans by means of a book written together with Skeeter. What is essential to note is the fact that by taking up this monumental task the black maids put their lives at risk. This illustrates that they are ready to resort to the most desperate measures in order to avoid abuse.

Through analysing shameful living and working conditions faced especially by black maids, whose lives are always under threat due to their colour of skin, The Help makes people aware of the problem of white supremacy and the damaging consequences of racist behaviour towards the Blacks. Together with the film of the same title as the book, which was released in 2011, The Help contributed a lot to changing white Americans' perception of African Americans. The movie "became one of the most commercially successful films so far in the twenty-first century" (Garcia, Young, and Pimentel 2014: 5) as it earned over 150 million dollars in domestic box office sales. In general, both white and black viewers of the film found it worth watching due to its excellent acting parts, well written script, and effective music. The novel as well as the film of the same title based on Stockett's book serve as an eye-opener to racially prejudiced white Americans helping them discern huge number of problems dealt with by the Blacks which were largely ignored or glossed over by the Whites over the centuries. It does not mean that The Help had great influence on all its readers and immediately opened their eyes on the obstacles the Blacks face every day. Nevertheless, such a production as The Help is a big step in fighting against racial discrimination towards African Americans which is still present in the USA today.

\section{References}

Better, Shirley Jean. 2002. Institutional Racism: A Primer on Theory and Strategies for Social Change. Lanham, MD: Rowman \& Littlefield.

Ezorsky, Gertrude. 1991. Racism and Justice: The Case for Affirmative Action. New York: Cornell University Press.

Fisher, P. Klaus. 2006. America in White, Black, and Gray: A History of the Stormy 1960s. New York: Continuum.

Foster-Singletary, Tikenya. 2012. Dirty South: The Help and the Problem of Black Bodies. Southern Quarterly Volume 49, Iss.4 (July). 95-107.

Garcia, Claire Oberon, Vershawn Ashanti Young, and Charise Pimentel. 2014. From Uncle Tom's Cabin to The Help: Critical Perspectives on White-Authored Narratives of Black Life. New York: Palgrave Macmillan.

Greenberg, Cheryl Lynn. 2009. To Ask for an Equal Chance: African Americans in the Great Depression. Lanham, Md: Rowman \& Littlefield Publishers. 
Hartman, Chester. 2014. The Help. In: Ida E. Jones, Daina Ramey Berry, Tiffany M. Gill, Kali Nicole Gross, Janice Sumler-Edmond (eds.), America's Growing Inequality: The Impact of Poverty and Race, 118-119. New York: Lexington Books.

Jones, Suzanne W. 2014. The divided reception of The Help. Southern Cultures Volume 20, Iss.1 (March). 7-25.

McHaney, Pearl. 2014. Kathryn Stockett's postmodern first novel. Southern Cultures Volume 20, Iss.1 (March). 77-92.

Mills, Fiona. 2016. Like One of the Family: Domestic Workers, Race, and In/Visibility in the Help. Cambridge: Cambridge Scholars Publisher.

Porter, Sam. 1993. Critical Realist Ethnography: the Case of Racism and Professionalism in a Medical Setting. New York: SAGE Publications.

Ruzich, Constance, and Julie Blake. 2015. Ain't Nothing Like the Real Thing: Dialect, Race, and Identity in Stockett's novel The Help. The Journal of Popular Culture Volume 48, Iss.3 (June). 534-547.

Stockett, Kathryn. 2009. The Help. London: Penguin Books Ltd.

Sturkey, William, and Jon N. Hale. 2015. To Write in the Light of Freedom: The Newspapers of the 1964 Mississippi Freedom Schools. Jackson: University Press of Mississippi.

Watson, Bruce. 2010. Freedom Summer: The Savage Season of 1964 that Made Mississippi Burn and Made America a Democracy. New York: Penguin Books Ltd.

Yanick St. Jean, and Joe R. Feagin. 1998. Double Burden: Black Women and Everyday Racism. Armonk, NY: M.E. Sharpe. 